\title{
O controle dos gastos públicos: problemas e sugestões
}

\section{Introduçāo}

O debate recente sobre a crise econômica brasileira tem ressaltado a necessidade de uma reforma institucional que contribua para uma clara definição de responsabilidades e um maior controle social sobre o Estado. Os componentes principais dessa reforma seriam a revisão das práticas orçamentárias e a meIhor identidade organizacional.

Do ponto de vista orçamentário, o primeiro aspecto a ressaltar é a perda de substância do Orçamento da União. Este deveria incluir a totalidade das contas fiscais, isto é, aquelas relacionadas à administração dos recursos extraidos compulsoriamente da sociedade através da tributação. A transferência de parte dessas contas para outros orçamentos - o monetário e o das "estatais" - reduziu a transparência da administração pública e tornou inoperante os mecanismos tradicionais de controle dos gastos do governo.

\section{Descentralizaçāo administrativa e diversificaçāo financeira}

A aplicaça indiscriminada dos princí- pios de descentralização administrativa preconizados pela Reforma de 1967 foi um dos fatores que contribuiram para o resultado mencionado. A passagem para Administração Indireta obedecia a interesses distintos, não guardando relação com a natureza das atribuições desempenhadas. Os administradores buscavam maior autonomia; os ministérios passavam a dispor de melhores condições para a contratação de funcionários; o poder executivo esquivava-se do controle; os interesses privados multiplicavam os canais de acesso a recursos administrados pelo Estado.

A relação entre o estatuto jurídico e a função desempenhada tornou-se cada vez mais frouxa. Fundaçōes assumiram a responsabilidade pela produção de bens públicos nos setores de saúde pública e proteção ambiental. Atividades auxiliares da administração, nos setores- de înformação e planejamento, passaram a ser exercidas, simultaneamente, por Autarquias, Fundações e Empresas Públicas. Algumas Universidades lograram transformar-se em Fundações, enquarito a maioria permaneceu enquadrada no regime das Autarquias. Ao não levar em conta a na- 
tureza da atividade exercıda, a concessão da autonomia administrativa não guardou relacão com as possibilidades de financiamento. Em alguns casos (processamento de dados e serviços gráficos, por exemplo), adotou-se o artificio da "venda" de serviços para o pro. prio Estado. Em outros, vinculou-se o produto de receitas fiscais, permanecendo, entretanto, a sustentação financeira das organizações na dependêncía de transferência, negociada ou compulsória, de recursos provenientes da receita tributária da União.

A descentralização administrativa das atividades públicas foi ainda acompanhada de uma grande diversificação dos mecanismos de financiamento das políticas governamentais, permitinda que os gastos do governo se expandissem muito além dos limites traçados por restrições a aumentos na carga tributária. Na realidade, a carga tributária líquida decresceu durante a década de setenta. após haver experimentado um breve crescimento durante a segunda metade dos anos sessenta. Assim, foi a crescente utilização de recursos não tributários que permitiu a rápida elevação dos dispêndios nesse período.

A expansão da dívida pública toì uma das principais formas de suprir o governo de recursos financeiros. A recuperação do crédito público, com a criação das Obrigações Reajustáveis do Tesouro Nacional, tinha, segundo argumentos da época, a finalidade de sanear as contas físcais e prover um instrumento não-inflacionário para o financiamento dos investimentos governamentais. Até 1971 o crescimento do saldo dos títulos da dívida pública em circulação no mercado manteve-se em níveis modestos, uma vez que sua expansão estava limitada pelo próprio crescimento do orçamento federal. Foi a partir de $1971^{1}$ que o governo decidiu abolir as restrições orçamentárias à expansão da dívida pública, tendo em vista consolidar o sistema de mercado aberto, através da emissão acelerada de títulos do Tesouro Federal.
Enquanto o mercado financeiro apresesentou condições propícias, a estratégia de bancar o serviço da dívida pela contínua expansão do saldo devedor funcionou a contento. $\mathrm{O}$ agravamento das dificuldades, no entanto, pôs a nu a fragilidade do sistema. De um lado, os custos da divida cresceram pelo aumento da taxa de juros - provocada pela própria pressão exercida pelo governo sobre o mercado - e pela aceleração infla cionária. De outro lado, as dificuldades de colocação conduziram a um aumento no volume e no prazo de retenção dos títulos públicos na carteira das autoridades monetárias. As estimativas atuis indicam que o volume de OATN e LTN em poder do Banco Central e do Banco do Brasil representam uma parcela significativa do total destes títulos em circulação no mercado.

\section{O orçamento e o controle dos gastos}

A metamorfose institucional, incentivada por vícios conhecidos do processo orçamentário, era, em grande número de casos, uma pura ficça. A diferença principal resultante dessa transtormaça passava a residir na forma de inserção das distintas organizacões no processo orçamentário. Enquanto as unidades da Administração Direta eram responsáveis por uma parcela dos gastos incluídos no orçamento geral do governo, as da Administração Indireta passavam a dispor de um orçamento próprio.

Do ponto de vista das organizações, a possibilidade de contar com um orçamento próprio seria uma forma de proteção contra os riscos de sucessivas revisões no orçamento geral. Como se sabe, a subestimativa da receita é uma prática usualmente adotada pelas autoridades centrais do sistema de orçamento. com o proposito de aumentar seu poder discricionário sobre a destinação dos recursos fiscais. Como os tetos inicialmente estipulados para cada unidade são baseados nas estimativas de crescimento da receita, o orçamento aprovado pelo Congresso no inicio do ano sofre suplementações posteriores em tace do "excesso de arrecadação". A subestimativa inicial serve, portanto, a dois propósitos: controla as oressões individuais para 
expansão dos gastos e reduz a interferência do poder legislativo sobre a utilização dos recursos pb́licos, uma vez que a distribuição do "excedente" é aprovada por decreto presidencial. Em tese, a subestimativa da receita pode ser utilizada como um instrumento da política antiinflacionária, caso ela seja utilizada para a geração de superávits no orçamento fiscal.

Em períodos de crise, o controle sobre o dispêndio das unidades orçamentárias lança mão de outro exediente: as chamadas reservas de contingência. Na prática, a aplicação das reservas de contingência significa a não liberação integral das cotas trimestrais da despesa orçamentária, cuja utilização posterior passa a depender do comportamento satisfatório da arrecadação. Dependendo da porcentagem do contingenciamento e dos critérios utilizados para a liberação dos re cursos, tal prática pode significar a substituição do orçamento escriturai pelo orçamento de caixa como lugar central das decisões sobre a distribuição das receitas públicas.

Se, no plano individual, a passagem pa ra a Administração Indireta "protege" as organizações contra os efeitos das práticas mencionadas, no plano coletivo a fragmentação institucional dificulta a correta interpretação dos resultados e o controle sobre as decisōes governamentais. Um problema, referese à conceituação e posterior aferição do déficit público. As unidades administrativas metamorfoseadas em instituiçöes autônomas não devem ser consideradas individualmente, uma vez que eventuais desequilibrios não traduzem, necessariamente, o desempenho da organização, mas sim o resultado de decisōes pretéritas e presentes sobre a repartição da receita de tributos. O déficit fiscal lou superávit) deveria ser apurado para o conjunto das organizações cujas atividades são financiadas por recursos extraídos compulsoria. mente da sociedade.

Como o objetivo inicial da criação da SEST era o de exercer controle sobre o orçamento das várias instituiçōes públicas, ou controladas pelo Estado، que não estavam inseridas no orçamento fiscal, o chamado Orçamento SEST é uma peça extremamente heterogênea do ponto de vista da natureza das instituiçōes envolvidas. Ai estão Autarquias, como as que integram o SINPAS, Fundações, como as da área universitária. Empresas Públicas, como o BNDES e o BNH, Sociedades de Economia Mista, como os grandes conglomerados de empresas estatais, além de empresas privadas temporariamente controladas pelo Estado. O fato de o Orçamento SEST ser comumente chamado de orçamento das Estatais deve-se, obviamente, à denominação da Secretaria que o administra. É claro que esse fato não teria maior importância não fosse a imagem dis. torcida que algumas vezes é transmitida à opinião pública quando se trata de apontar os alegados "descaminhos da estatização".

A junção num mesmo orçamento de unidades heterogêneas traz, todavia, outros prolemas que não os de natureza puramente semântica. Consideremos, inicialmente, as instituições tipicamente governamentais, cuja receita provém, essencialmente, de contribuições compulsórias /físcais ou parafis cais arrecadadas diretamente ou transferidas do orçamento federal. Grande parte dessas instituições (a exceção mais importante é o SINPAS) obteve sua relativa autonomía como decorrência do processo de descentralização impuisionado pela Reforma Administrativa de 1967, que incentivou a fragmentação institucional do governo. Dada a natureza eminentemente pública de suas funções, a idéia de que cada uma delas isoladamente possa apresentar déficit é tão equivocada quanto a seria afirmar que uma unidade qualquer do orçamento público é deficitária. $A$ inclusão desșas instituições no Orçamento SEST afeta o correto entendimento das contas governamentais, uma vez que um grande número de instituiçôes da Administração Descentralizada controladas pela SEST é responsável por programas de amplo interesse social, nas áreas de educação, saúde, assis- 
tência social, nutrição, etc... Poderíamos, por exemplo, dizer que a descentralização administrativa propiciou a gestão de superávits no orçamento fiscal ao reduzir-lhe a responsabilidade no financiamento de programas sociais. A transferência desse superávit para o orçamento das estatais ou para o orçamento monetário não significa، assim, que - governo foi obrigado a conter a expansão das funções públicas em face da presença indevida do Estado em atividades mais propícias à iniciativa privada, como tem sido afirmado. Ao contrário, a interpretação correta é a de que os superávites decorrem da opção institucional adotada, que pretendia, através da descentralização, transferir ao usuário uma parcela maior de responsabilidade pelo financiamento direto de programas sociais. reduzindo sua dependência de recursos fiscais. A clara separação das instituições que integram o orçamento SEST e a apuração conjunta do saldo orçamentário referente á execução das funções tipicamente governamentais constituiriam, portanto, passos importantes para o correto entendimento do problema.

Quanto às empresas estatais propriamente ditas, a controvérsia refere-se ao critério utilizado para apropriação do déficit. A reunião de instituições distintas em um mes. mo orçamento levou a medição do déficit das empresas pelo critério usual do saldo entre receitas e despesas totais. No caso das empresas, entretanto, é importante estabelecer distinção entre o déficit operacional, o déficit não-operacional e as necessidades líquidas de recursos para financiamento dos investimentos. Com exceção de algumas empresas de servicos públicos - o caso mais importante sendo o da Rede Ferroviária Federal - o déficit das estatais brasileiras não é, predominantemente, de natureza operacional. Uma boa parte dos desequilíbrios recentes foi provocada por uma elevação dos custos financeiros decorrente do endividamento externo e posteriores desvalorizações cambiais, ainda que a captação de emprésti- mos tivesse sido parclalmente induzida por interesses gerais da política econômica e não por necessidades próprias das empresas. Nesse caso, a despesa financeira lançada a débito da empresa pode provocar um déficit nãooperacional, mas esse resultado não pode ser utilizado como indicador da ineficiência do Estado-empresário.

O ponto mais importante, no entanto, é o do financiamento dos investimentos. Ninguém espera que uma grande empresa capitalista financie integralmente o seu processo de expansão pela reinversão dos próprios lucros. A captação de recursos de terceiros, sob a forma de capital de empréstimo ou de risco. é a regra predominante no mundo dos negócios, variando a estrutura de financiamento em função do estágio de desenvolvimento do mercado de capitais, das perspectivas de expansão do setor e dos interesses do grupo contralador. Nesse caso, o que justifica o tratamento assimétrico das contas das empresas estatais? Por que agregar ao déficit do setor público as necessidades líquidas de financiamento das Sociedades de Economia Mista? Não só essa parcela não pode ser considerada como déficit, no sentido pejorativo de íneficiência ou irresponsabilidade normalmente associado ao termo, como também a sua contabilização como déficit do setor público constizui um procedimento equivocado. Pode-se, obviamente, falar de um desequilíbrio entre o programa geral de investimentos eas possibilidades atuais de financiamento. A solução para este desequilíbrio não está, entretanto, no corte generalizado de investimen-. tos, mas sim na retomada de um planejamento de longo prazo que vise a assegurar maior consistência das metas de expansão.

O esvaziamento do Orçamento da União, do ponto de vista de sua representatividade como instrumento financeiro do planejamento governamental, tem uma outra face pouco conhecida. Trata-se das despesas invisiveis, representadas por um extenso conjunto de isenções, deduções, incentivos e outros benefícios fiscais. O montante de recur- 
sos direcionados aos setores contemplados com tais beneficios assume proporçōes consideráveis، mas não são facilmente reconhecidos, devido à ausência de registros contábeis. A substituição dos gastos diretos por "despesas tributárias" é, portanto, uma das formas de se reduzir a transparência das ações governamentais e a eficácia dos instrumentos usuais de controle. Na prática, as despesas tributárias são representadas pela receita "não-arrecadada", em decorrência da crescente utilização dos tributos como instrumento mais geral da política econômica. Estimativas parciais do montante dessas "despesas" indicam que o efeito inibidor que elas exercem sobre as possibilidades de ampliação dos gastos sociais do Estado é muito mais importante do que o que tem sido atribuido ao alegado desvio de superávits fiscais.

\section{A revisòo do processo orçamentário}

Na versão atual, o Orçamento da União iclui: a) gastos realizados por órgãos da Administração Direta; b) transferências intergovernamentais (para estados e municípios); c) transferências intragovernamentais (para órgãos da Administração Indireta federal); d) transferência para o Orçamento Monetário (recente). Assume, portanto, uma função cada vez mais próxima de um orçamento de transferèncias, como fruto da acentuada concentração da recejta tributária e da excessiva fragmentação institucional.

Enquanto houve uma preocupação em incluir a maior parte das receitas fisca is no orçamento, a descentralização administrativa dele retirava as unidades de gastos, desequilibrando os dois pratos da balança. O contrapeso, cada vez mais saliente, passava a ser representado pelo volume de transferências. De início, o controle sobre essas transferências era insignificante, uma vez que a maior parte das receitas tributárias das Autarquias e Fundações (com exceção da Previdência Social) era automaticamente repassa- da aos respectivos orçamentos. O trânsito desses recursos pelo Orçamento da União não passava, portanto, de um simples regis. tro contábil. A progressiva desvinculação (com a criação do FND, por exemplo) alterou esse quadro, na medida em que a participação de cada órgão deixou de ser fruto de regras preestabelecidas, submetendo-se à competição por recursos incluidos no bolo geral. Se a autonomia financeira é um atributo importante para a autonomia jurídica, e para a livre disposição dos recursos, as modificações nas regras do jogo eliminaram um dos incentivos importantes à descentralização e igualaram as instituições públicas, não obstante a diversidade de estatutos jurídicos.

A opção adotada para contornar a perda de substância do Orçamento da União considerada uma medida positiva para enfrentar uma situação de emergência, que exige um maior controle administrativo sobre o dispêndio público. A própria experiència da SEST indica, no entanto, as dificuldades decorrentes do tratamento uniforme de organizações heterogêneas. Um problema, jă amplamente debatido, é a atribuição de idêntico significado a desequiljbrios financeiros apresentados por empresas estatais ou por organizações burocráticas. Outro problema é a tendência à padronização de critérios para elaboração dos orçamentos e acompanhamento das empresas públicas num figurino orçamentário inadequado às características da organização.

A redefinição do conteúdo dos vários orçamentos seria um primeiro passo no sentido da correção de alguns problemas apontados. Trata-se, em primeiro lugar, de tornar mais abrangente o Orçamento da União, incorporando a ele as instituições da Administração Indireta que não têm caráter empresarial e que estão indevidamente incluídas no orçamento SEST. Numa reforma mais profunda, o Orçamento da União passaria a ser constituído das seguintes partes:

a) o Orçamento de gastos da Administraç̃o Direta; 
b) O Orçamento dos Orgãos Autônomos (Autarquias e Fundações):

c) o Orçamento de subsidios e "despesas tributárias", incluindo subsidios à produção e ao consumo (parcialmente incluidos, hoje, no orçamento monetáriol e a estimativa das vantagens concedidas através das várias modalidades de benefícios fiscais.

A redefinição do conteúdo dos orçamentos irá exigir, também, uma reavaliação dos critérios utilizados para a classificação das contas governamentais. As grandes categorias de receitas e despesas (correntes e de capital) previstas no sistema orçamentário são insuficlentes do ponto de vista analítico e induzem, com freqüência, a erros de julgaento. Propõe-se adotar outro critério: elaborar um orçamento de expansão e um orçamento de manutenção. Este último incluiria os gastos (e recursos) necessários à manutenção das atividades existentes, nos níveis correspondentes à capacidade produtiva instalada. O orçamento de expansão, por outro lado, deveria abranger a previsão de recursos necessários à ampliação do atendimento, tanto os referentes a investimentos quanto os acréscimos correspondentes nas necessidades de manutenção. Essa distinção é importante para a correta interpretação dos desequilíbrios financeiros. Desequilíbrios provocados por programas de expansão não têm, obvilamente, o mesmo significado que aqueles decorrentes da indisponibilidade de receitas ordinárias para cobrir as despesas operacionais. Especialmente no que se refere às empresas estatais, o déficit de recursos decorrentes de planos de expansão não configura uma situação "anormal" uma vez que essa é a regra aplicável ao mundo empresarial.

\section{A reforma institucional eos meconismos de controle}

Além da revisão orçamentária, o momento é também propicio a modificações na estrutura administrativa. Se o modelo preconizado pela Feforma de 1967 buscava ajustar a máquina governamental a uma estratégia de desenvolvimento voltada para o crescimento rápido, a inversão de expectativas recomenda uma mudança de atitude. A ênfase no atendimento das necessidades básicas da população menos favorecida implica no fortalecimento da Administração Direta. A transferência para a Administração IndireA transferência para a Administração Indireta de boa parte da responsabilidade por programas sociais nas áreas de saúde, nutrição e educação, não favorece aos propósitos de eqüidade na repartição dos benefícios dos gastos públicos.

A apreciação individual de cada caso deverá indicar um bom número de Autarquias, Fundações e, até mesmo, Empresas Públicas, cuja permanência nessas categorias não mais se justifica, uma vez que teriam se esgotado os motivos originais para sua constituição. Além disso, será importante reavaliar os critérios nas escolhas referentes à forma organizacional adotada para a execução de distintas atividades públicas.

O que diferencia uma Empresa Pública de uma Sociedade de Economia Mista? E uma Autarquia de uma Fundação? Segundo as definições contidas no Decreto- Lei 200/67:

a) Autarquias - serviços autônomos com personalidade jurídica, patrimônio e receita própría, criados por lei para executar atividades típicas da administração pública, que requeiram, para seu melhor funcionamento, gestão financeira descentralizada.

b) Empresas Públicas - entidades dotadas de personalidade jurídica de direito privado, com patrimônio próprio e capital exclusivo da União ou de suas entidades da Administração Indireta, criadas por lei para desempenhar atividades de natureza empresarial que o governo seja levado a exercer, por motivos de conveniência nu contingência ad- 
ministrativa, podendo tal entidade revestir-se de qualquer das formas admitidas em direito. Equiparam-se às empresas públicas, para os efeitos da lei da Feforma Administrativa, as fundações instituidas em virtude de lei federal e de cujos recursos participe a União, quaisquer que sejam sua finalidades.

c) Sociedades de Economia Mista - entidades dotadas de personalidade jurídica de direito privado, criadas por lei para o exercicio de atividade de natureza mercantil, sob a forma de sociedade anônima, cujas ações com direito a voto pertençam, em sua maioria, à União ou à entidade da Administração Indireta.

Como não há uma referência explícita à natureza da atribuição busca-se o estatu to jurídico que garanta maior autonomia, o que contribui para uma perda de identidade institucional. Atividades auxiliares da administração, como processamento de dados, serviços gráficos, estudos e pesquisas organizam-se sob a forma de empresas públicas. Serviços públicos urbanos, tradicionalmente a cargo da Administração Direta local, passam à responsabilidade de Sociedades de Economia Mista, Autarquias e Fundaçōes e distinguemse mais pela época de criação do que pela natureza das atividades.

Cabe notar que a Reforma Administrativa de 1967 previa um completo sistema de controle da Admínistração Pública, baseado na supervisão ministerial e na integração dos ministérios ao sistema nacional de planejamento. Nesse sistema, os colegiados deveriam fornecer suporte à supervisão ministerial, intermediando os interesses públicos e privados envolvidos em uma determinada política. A lei da Reforma Administrativa desce a detalhes quanto a medidas para o exercício da supervisảo ministerial, como neste exemplo: indicação pelo Ministro de Estado dos candidatos a postos diretivos nas sociedades de Economia Mista e Empresas Públicas a ele subordinadas; designação, pelo mi- nistro, dos representantes do governo federal nas assembléias-gerais e conselhos de administração e controle; aprovação de contas, relatórios e balanços diruiamente ou através de seus representantes. Além desses e de outros mecanismos de controle administrativo, o sisterna prevê a possibilidade de o Congresso solicitar, a qualquer momento, através do ministro responsável, as informações que julgar necessárias ao acompanhamento das atividades das empresas estatais.

O fracasso da supervisão ministerial tem sido atribuido a diversos fatores, entre eles a melhor capacidade técnica das empresas em relação aos órgãos encarregados de sua supervisão. Nesse caso, a incapacidade de avaliar o mérito da atuação voltou o controle para aspectos puramente formais, esvaziando as dimensōes econômicas e políticas do processo. Além disso, o formalismo do sistema deixou de lado uma recomendação da maior importância para o funcionamento do mecanismo de supervisão ministerial: a de os ministros da área serem responsáveis pela nomeação (e demissão) dos dirigentes das empresas a eles vinculados.

O enfoque administrativo não aborda uma questão fundamental na análise dos problemas de controle: o da inserção das empresas públicas no espaço politico que delimita os interesses envolvidos em uma determinada política governamental. A tragmentação institucional do Estado brasileiro esvaziou o núcleo central do governo, multiplicando as esferas de decisão e os canais de acesso dos distintos interesses privados a decisőes de política. A autonomia de agências da Administração Indireta explicar-se-ia, portanto, pelo maior comando que elas exercem subre os recursos mobilizados para a implementação da política - principalmente os de natureza financeira. A existência de várias arenas decisórias dificulta o controle governamental. Do lado do setor público, a visão que cada agente tem do todo é parcial e incompleta, pela falta de transparência do processo deci- 
sórı. Do lado dos interesses privados a possibilidade de recorrer a instâncias diversas pode aumentar suas chances de obter maiores vantagens na negociação.

Forma-se, cada vez mais, na sociedade brasileira, a convicção de que o controle da expansão do Estado depende mais do funcionamento das instituições políticas que. num regime democrático, garantem a adequada representação de interesses, do que de reformas de cunho puramente administrativo. E preciso aumentar a transparência das políticas públicas, desobstruir os canaís de participação da sociedade nas decisões de interesse coletivo e assegurar maior eqüidade na representação dos distintos interesses no processo decisório.

Uma reforma instituciona! que busque uma relação mais nítida entre o estatuto jurídico e a natureza das atribuições exercidas pelas distintas organizações públicas constitui um passo importante para a desejada transparência dos gastos públicos. Critérios a serem observados nas decisões sobre a forma organizacional seriam a origem do financiamento e a natureza das atribuições. Enquanto o financiamento compulsório caracteriza as atribuições coletivas, a contribuição direta do usuário (ou consumidor) estabelece uma referência importante para a organização empresarial. Quanto à natureza das atribuições, o caráter social do empreendimento deve ter um papel decisivo na escolha do tipo de organização.

O atual universo das Sociedades de Economia Mista inclui um grande número de empresas voltadas para a produção de serviços urbanos que se relacionam ao atendimento de necessidades básicas da população: ågua e esgoto, iluminação pública e transportes coletivos, por exemplo. Em tese, essas empresas ajustam-se mais ao conceito de empresas públicas que ao de sociedades de economia mista. Esta segunda categoria deveria ser reservada a atividades públicas direta- mente relacionadas ao setor produtivo da economia, correspondendo ao que é algumas vezes definido como o setor produtivo esta. tal. Tal distinção permitiria estabelecer normas operacionais diferentes, tendo em vista um melhor funcionamento dos instrumentos de controle. As normas estabelecidas pela lei das sociedades anônimas continuariam regendo o funcionamento das empresas do setor produtivo estatal, enquanto a prestaçāo de serviços seria enquadrada no estatuto das empresas públicas, que deveria ser reexaminado no sentido de permitir uma adequada representação da comunidade nos colegiados que controlam a gestão da empresa.

O novo orçamento das estatais, expurgado das instituições que não exercem atividade empresarial, passaria a ser composto por dois subconjuntos: o orçamento das Empresas Públicas e a das Sociedades de Econo. mia Mista. Essa distinção é importante do ponto de vista da proposta de uma melhor definição de responsabilidades entre os três niveis de governo. A prestação de serviços urbanos por empresas públicas deveria ser transferida à responsabilidade dos governos locais, eliminando-se a centralização que hoje se verifica do ponto de vista da defini. ção de prioridades, normas gerais de operação, política tarifária e mecanísmos de controle. A descentralização do processo decisório permitiria uma maior representação da comunidade - inclusive um numeroso continge de não-consumidores - em decisões relevantes para a qualidade de vida da população urbana.

Quanto às Sociedades de Economia Mista, que reuniriam principalmente as empresas estatais ligadas à produção de insumos básicos para a indústria, o problema atual não é a centralização do controle, mas sim a necessidade de esse controle ser integrado à política industrial e à política macroeconô. mica como um todo.

A redefinicão do conteúdo dos vários 
orçamentos é um passo importante para os propositos de se obter um maior controle político sobre os gastos públicos. A simples consolidação dos orçamentos, a partir das categorias hoje existentes, terá eficácia duvidos, uma vez que o julgamento do mérito das propostas fica prejudicado pela dificuldade de avaliação.

\section{Noto}

1 Lei Complementar n! 12, de 8/11/71. 